\title{
An anthropological perspective on "occupation": A study of older adults' motivations for learning and using computer technology
}

\author{
Molly Harrod, PhD \\ Post-doctoral Fellow, Ann Arbor Veterans Affairs Health Services \\ Research and Development Center of Excellence
}

Daily occupations consist of activities that provide some type of capital, be it social, cultural, or symbolic (Bourdieu, 1977) to the individuals involved. Engagement in these activities provides meanings that extend beyond the "doing" and also represent the social roles these individuals find to be culturally salient. But, what is often not known is why individuals choose to participate in specific activities, their motivations and what these activities represent to them on larger social and cultural levels. This study looked at such socially and culturally constructed motivations in addition to the hopes and fears older adults may face when they are learning and engaging in new activities. How older adults defined being "successful" in their everyday occupations was also examined to understand how these notions relate to the larger, macro-level ideas about what it means to be a "successfully aging older adult" within the United States.

Using classic anthropological methods, I studied older adults' ideas about fears, hopes, and successes regarding computer learning. For this brief description, I will focus on the culturally constructed notion of fear to demonstrate how better understanding the capital sought and provided by activities can offer deeper insights into individual and collective notions of success and how older adults go about reaching their learning goals through taking on new activities. SeniorNet ${ }^{\circledR}$, an older adult-oriented computer learning center was the research site for this study. During this study, I found that SeniorNet ${ }^{\circledR}$ views older adults as having special needs when it comes to learning technology. These special needs are thought to include fears that must be overcome if older adults are to be successful in their technological learning. To give just one example, SeniorNet ${ }^{\circledR}$ had devised specific teaching strategies to address the program's overall perception that older adult computer learners would be fearful of breaking the computer.

From the older adult computer learner perspective, one of the most common fears mentioned was the "fear of being left behind". Many older adults interviewed felt that society was technologically "moving beyond" them and that this situation would impact their social relations with family and friends. But, this fear also motivated them to learn the computer thus maintaining a "sense of control". During participant observation in the SeniorNet ${ }^{\circ}$ computer lab as well as in interviews, these adults described attempting to locate themselves in a technological environment that they often perceive is playing a much larger role in the lives of the younger generations. For instance, being able to "talk technology" gave these older adults a highly relevant topic for communication with younger family members and sometimes helped prevent the feelings that they were "losing touch" with younger family members. Over time, I learned that fear went well beyond the notion of simply breaking the computer and incorporated how the older adults wanted to view themselves in addition to how they wanted others to see them in this society.

To extend this point further, the older adults in this study felt that they "needed" to learn to use computers in order to help maintain their social roles and continue to feel "vital" within American society. They did not necessarily need to become experts at computer usage, it was enough for them to be able to demonstrate to themselves and more so, to others, that they could learn new things and continue to participate at all levels of society. In the educational habitus studied, they sought to acquire cultural capital associated with being a specific kind of older adult namely, one who can learn and use the computer. For some, this path was much easier than for others. However, most continued to work at mastering the computer because they wanted to be seen as the kind of older adult who is an active, independent functioning participant in American society, engaging in the same way as younger members. It is important to note here that this study did not focus on older adults who chose not to engage in computer learning in this SeniorNet ${ }^{\circledR}$ environment. Understanding why some older adults choose not to engage in certain occupations, including computer learning and new technology adaptation, will be an interesting question to consider in future research.

Through this gerotechnology related example, I have aimed to show how anthropological methodologies and use of theory can contribute to better understanding how daily activities come to be incorporated into older adults' daily lives. As indicated above, this includes understanding their motivations, fears, learning processes and successes they gain through engagement. These types of understandings can aid in constructing programs that support older 


\section{Perkinson and Briller, continued from p. 26}

of a new house, to convey the experience of venturing into a new place (either physical or intellectual) and thoroughly exploring it, room-by room. This orienting metaphor enabled him to discuss quite eloquently how he viewed the "fun" (aka intellectual excitement) of throwing open the doors and seeing what one finds in these rooms. Upon entering each new room, one can see what is already there and the overall dimensions and characteristics of these spaces. Sometimes one knows about key aspects of what one will find there, and sometimes one is surprised as well. Opening these doors also presents opportunities to think about how the various "rooms" in the house fit together and can be coordinated over time. He captured the excitement that comes at the beginning of such an exploration and recommended paying close attention to all aspects of this discovery process, keeping the "big picture" in mind and never forgetting the fundamentals of each field - e.g., what makes the framing of a particular issue anthropological, and likewise for OT. The "good bones" of the anthro-OT house, with its strong foundation and supporting structures, should provide an appropriate environment that will foster the continued growth of our cross-disciplinary dialogue.

In spite of its time slot (i.e., the last morning of the conference), it was clear that the session had an impact. There was much post-session discussion in the hallway about individual papers, the discussants' comments, and where to go from here; so much so that several people expressed concern about making it to the airport in time to catch their flights. We, as the session organizers, took it as a good sign that this conversation continued, that there was enthusiasm for ongoing exploration of this linkage, and it fortified us for taking this work forward. We hope that you will enjoy reading about these issues, learning about what has been discussed so far, and adding your own voices and perspectives to extending this conversation.

\section{References:}

American Occupational Therapy Association (AOTA). 2008. Occupational Therapy practice framework: Domain $\mathcal{E}$ process. $2^{\text {nd }}$ edition. Bethesda, MD: The American Occupational Therapy Association, Inc.

Block, P., Frank, G. \& Zemke, R. 2008. Practicing Anthropology (Special issue on Anthropology and Occupational Therapy), 30(3).

Frank, G. 2007. Occupational Therapy \& Occupational Science Interdisciplinary Interest Group: A proposal to the National Association for the Practice of Anthropology.

Inhorn, M. 2007. Medical anthropology at the intersections. Medical Anthropology Quarterly, 21(3): 249-55.

Kronenberg, F., Algado, S. \& Pollard, N. 2005. Occupational therapy without borders. Edinburgh: Elsevier/Churchill Livingstone.

Law, M., Polatajko, H. Baptiste, W. \& Townsend, E. 1997. Core concepts of occupational therapy. In E. Townsend (Ed.), Enabling occupation: An occupational therapy perspective (pp. 29-56). Ottawa, ON: Canadian Association of Occupational Therapists.

Pollard, N., Sakellariou, D. \& Kronenberg, F. 2009. A political practice of occupational therapy. Edinburgh: Elsevier/ Churchill Livingstone.

Schatz, continued from page 27

the individuals' "life opportunities." In all likelihood, most of them will become practitioners, not researchers, but this experience allows them to see why evidence-based practice is important and how an interdisciplinary lens enhances both their field and others.

Harrod, continued from page 29

adults' interest in not only "doing something" but also "being someone", and for these participants, that meant being recognized as active, engaged, independent and therefore, vital contributing members within American society. Going forward in extending this research program, I look forward to drawing upon and integrating a variety of disciplinary perspectives that can inform this work from anthropology, gerontology, occupational science/occupational therapy, and technology studies, to list some relevant areas here. 